\title{
Proton pump inhibitors use and risk of developing spontaneous bacterial peritonitis in cirrhotic patients: A systematic review and meta-analysis
}

Saad Alhumaid ${ }^{1 *}$ (D) Abbas Al Mutair ${ }^{2,3,4}$ (D), Zainab Al Alawi ${ }^{5}$, Abdul Rehman Zia Zaidi ${ }^{6,7}$, Ali A. Rabaan ${ }^{8}$, Alyaa Elhazmi ${ }^{6}$ and Awad Al-Omari ${ }^{6,7}$

\begin{abstract}
Background: Spontaneous bacterial peritonitis (SBP) is one of the most common infectious diseases in patients with cirrhosis and is associated with serious prognosis. A prevailing dogma posits that SBP is exacerbated by the frequent use of proton pump inhibitors (PPIs).

Aims: To re-assess the association between PPIs use and SBP incidence with larger and better-quality data.

Method: The studies were identified by searching Proquest, Medline, and Embase for English language articles published between January 2008 and March 2020 using the following keywords alone or in combination: anti-ulcer agent, antacid, proton pump inhibitor, proton pumps, PPI, omeprazole, rabeprazole, lansoprazole, pantoprazole, esomeprazole, peritonitis, spontaneous bacterial peritonitis, SBP, ascites, cirrhosis, ascitic and cirrhotic. Three authors critically reviewed all of the studies retrieved and selected those judged to be the most relevant. Preferred Reporting Items for Systematic Reviews and Meta-Analyses (PRISMA) statement was followed. Pooled odds ratios (ORs) with 95\% confidence intervals ( $\mathrm{Cls}$ ) were calculated. Sub-group analyses were done to decrease the heterogeneity.

Results: A total of twenty-three studies: seven case-control, and sixteen cohorts, involving 10,386 patients were analyzed. The overall results showed a statistically significant association between SBP and PPIs use (pooled odds ratio (OR): $1.80,95 \% \mathrm{Cl}$ of 1.41 to 2.31 ). Substantial heterogeneity was observed. On subgroup analysis involving cohort studies, the association was weaker (OR: 1.55 with $95 \% \mathrm{Cl}$ of 1.16 to $2.06 p<0.00001$ ) but still statistically significant and with high heterogeneity $\left(\mathrm{Chi}^{2} \mathrm{p}=57.68 ; \mathrm{P}^{2}=74 \%\right)$. For case-control studies, the OR was 2.62 with a $95 \% \mathrm{Cl}$ of 1.94 to 3.54. The funnel plot was asymmetric and Egger's test confirmed asymmetry suggesting publication bias (intercept $=-0.05, \mathrm{SE}=0.27, \mathrm{P}=0.850$ two-tailed).

Conclusion: This meta-analysis sheds light on the conflicting results raised by previous studies regarding the association of SBP with PPIs use. Our meta-analysis showed that there is a weak association, although statistically significant, between SBP and PPIs use. However, the magnitude of the possible association diminished when analysis focused on higher quality data that were more robust. Thus, this updated meta-analysis suggests judicious use of PPIs among cirrhotic patients with ascites.
\end{abstract}

*Correspondence: saalhumaid@moh.gov.sa

${ }^{1}$ Administration of Pharmaceutical Care, Al-Ahsa Health Cluster, Ministry of Health, Al-Ahsa, Saudi Arabia

Full list of author information is available at the end of the article

(c) The Author(s) 2021. This article is licensed under a Creative Commons Attribution 4.0 International License, which permits use, sharing, adaptation, distribution and reproduction in any medium or format, as long as you give appropriate credit to the original author(s) and the source, provide a link to the Creative Commons licence, and indicate if changes were made. The images or other third party material in this article are included in the article's Creative Commons licence, unless indicated otherwise in a credit line to the material. If material is not included in the article's Creative Commons licence and your intended use is not permitted by statutory regulation or exceeds the permitted use, you will need to obtain permission directly from the copyright holder. To view a copy of this licence, visit http://creativecommons.org/licenses/by/4.0/. The Creative Commons Public Domain Dedication waiver (http://creativecommons.org/publicdomain/zero/1.0/) applies to the data made available in this article, unless otherwise stated in a credit line to the data. 
Keywords: Ascites, Cirrhosis, Meta-analysis, Proton pump inhibitors, Spontaneous bacterial peritonitis, Systematic review

\section{Introduction}

Spontaneous bacterial peritonitis (SBP) is defined as an ascitic fluid infection without an evident intra-abdominal surgically treatable source. Despite timely diagnosis and treatment its reported incidence in ascitic patients varies between 7 and 30\% [1]. SBP should be suspected in a patient with ascites and any of the following: temperature greater than $37.8{ }^{\circ} \mathrm{C}\left(100^{\circ} \mathrm{F}\right)$, abdominal pain and/ or tenderness, a change in mental status, or ascitic fluid polymorphonuclear leukocyte (PMN) count $\geq 250$ cells/ $\mathrm{mm}^{3}$ [2]. SBP is one of the most common infectious diseases in patients with cirrhosis and is associated with a serious prognosis [3]. In-hospital mortality from SBP is estimated at $11-67 \%$ [4].

SBP is exacerbated by the frequent use of proton pump inhibitors (PPIs) in cirrhotic patients with ascites, leading to a reduction in gastric acidity and an increase in intestinal permeability which promotes bacterial translocation and colonization of mesenteric lymph nodes [5]. Subsequent infection of the fluid in the peritoneal cavity is also facilitated by the impairment of the body's defense mechanisms [6].

The use of PPIs has been widely reported to be associated with a higher incidence of SBP in hospitalized cirrhotic patients [7-11]. However, previous studies including case controls $[7,10]$, cohorts $[8,9,11]$, and meta-analyses [12-14] provided conflicting conclusions. In light of newer studies that were done to re-evaluate the causality of PPI use and development of SBP, we aimed to re-assess the association between PPI use and SBP incidence with larger and better-quality data.

\section{Methods Design}

We followed the Preferred Reporting Items for Systematic Reviews and Meta-Analyses guidelines (PRISMA) in conducting this systematic review and meta-analysis [16]. The following electronic databases were searched: PROQUEST, MEDLINE, and EMBASE with Full Text. Search keywords included anti-ulcer agents, antacids, proton pump inhibitors, proton pumps, PPI, omeprazole, rabeprazole, lansoprazole, pantoprazole, esomeprazole, peritonitis, spontaneous bacterial peritonitis, SBP, ascites, cirrhosis, ascitic and cirrhotic. The search was limited to papers published in English, between 1 January 2008 and 31 March 2020. The title and abstract of each selected article were read, and the article was retained if it discussed the use of PPIs and the development of SBP. A manual search through the bibliographies of the retrieved publications (backward snowballing) was conducted to increase the yield of potentially relevant articles.

\section{Inclusion-exclusion criteria}

Articles were eligible for inclusion in this review and meta-analysis when they met all of these criteria: (1) observational study, including case control, and cohort study evaluating the risk of SBP associated with PPI therapy; (2) study population comprised adult patients ( $\geq 18$ years); (3) SBP (defined as $\geq 250$ polymorphonuclear leukocytes in the ascitic fluid) was a study endpoint; (4) hospital- or community-based study; and (5) date of publication between 2008 and 2020 in the English language. Articles were excluded if they met one of the following criteria: (1) editorials, commentaries, news analyses or reviews; (2) no control group of patients; (3) PPI therapy usage data (the type of therapy and who received the drug) was not available or could not be extracted, and (4) data were presented based on SBP episodes and not on the number of actual patients.

\section{Data extraction}

Three authors (S.A., A.A. and Z.A.) critically reviewed all of the studies retrieved and selected those judged to be the most relevant. The abstracts of all citations were examined thoroughly. Data were extracted from the relevant research studies using key headings, which are noted in Table 1, simplifying analysis, and review of the literature. Articles were categorized as a case-control or a cohort study. The following data were extracted from selected studies: authors; publication year; study location; study design and setting; sample size, age, gender, and follow-up; statistical adjustment for confounders; and Newcastle-Ottawa Scale (NOS) score.

\section{Quality assessment}

Newcastle-Ottawa Scale (NOS) was used to assess the quality of the selected studies [15]. This assessment scale has two different tools for evaluating case-control and cohort studies. Each tool measures quality in the three parameters of selection, comparability, and exposure/ outcome, and allocates a maximum of 4,2 , and 3 points, respectively. High-quality studies are scored greater than 7 on this scale, and moderate-quality studies, between 5 and 7. Quality assessment was performed by two authors (SA and AA) independently, with any disagreement to be resolved by consensus. 


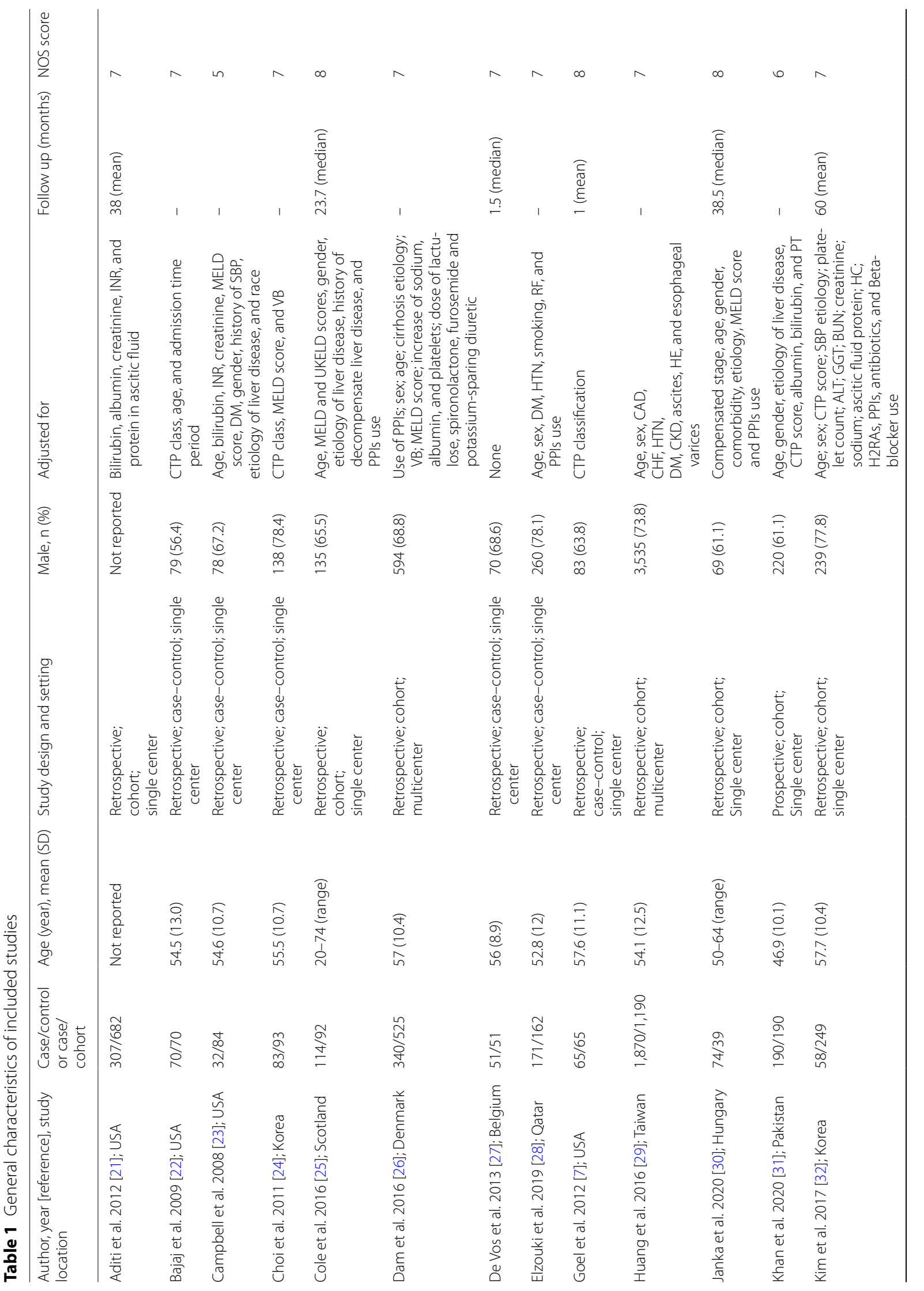




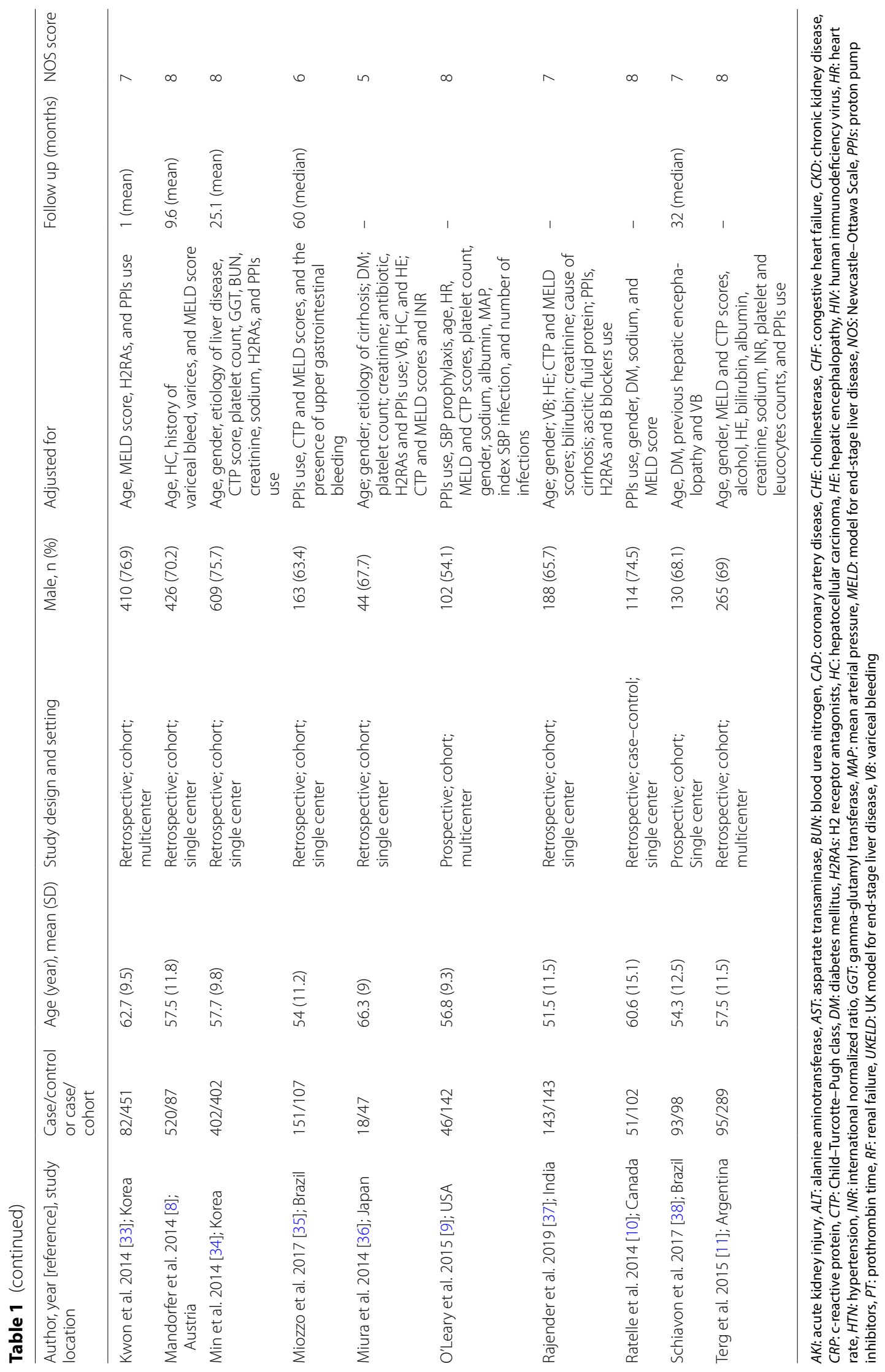




\section{Data analysis}

Meta-analyses were performed to calculate pooled odds ratios (ORs) with 95\% confidence intervals (CIs). The similarity between the OR and other relative measures, such as RR, was assumed because SBP events and deaths were rare [17]. When both the crude and the adjusted OR/RR values were offered, only the adjusted value was adopted for the meta-analysis. If only the raw data was reported, we would calculate the unadjusted OR. Taking a conservative approach, a random effects model was used, which produces wider CIs than a fixed effect model.

Statistical heterogeneity was evaluated using the Cochran's chi-square $\left(\chi^{2}\right)$ and the $I^{2}$ statistic [18]. An $I^{2}$ value of $>50 \%$ is suggestive of significant heterogeneity [19]. To detect the source of heterogeneity, subgroup analysis was performed based on study design (case-control or cohort), and quality of studies (high or moderate quality study). A sensitivity analysis was performed by excluding studies with relatively lower methodological quality. Publication bias was evaluated using funnel plots and the Egger's correlation test, with $\mathrm{P}<0.1$ indicating statistical significance [20]. Review Manager (Version 5.3, Oxford, UK; The Cochrane Collaboration, 2014) and Stata (Version 13.0, Stata Corp, College Station, TX) were used to carry out all statistical analyses.

\section{Results}

\section{Study characteristics and quality}

A total of 178 publications were identified (Fig. 1). After scanning titles and abstracts, we discarded 86 duplicate articles. Another 18 irrelevant articles were excluded based on the titles and abstracts. The full texts of the 39 remaining articles were reviewed, and 16 irrelevant
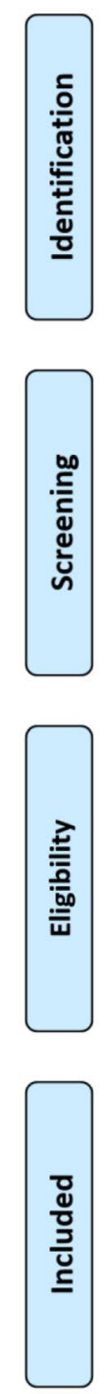

Records identified through database searching $(n=173)$
Additional records identified through other sources ( $n=5)$

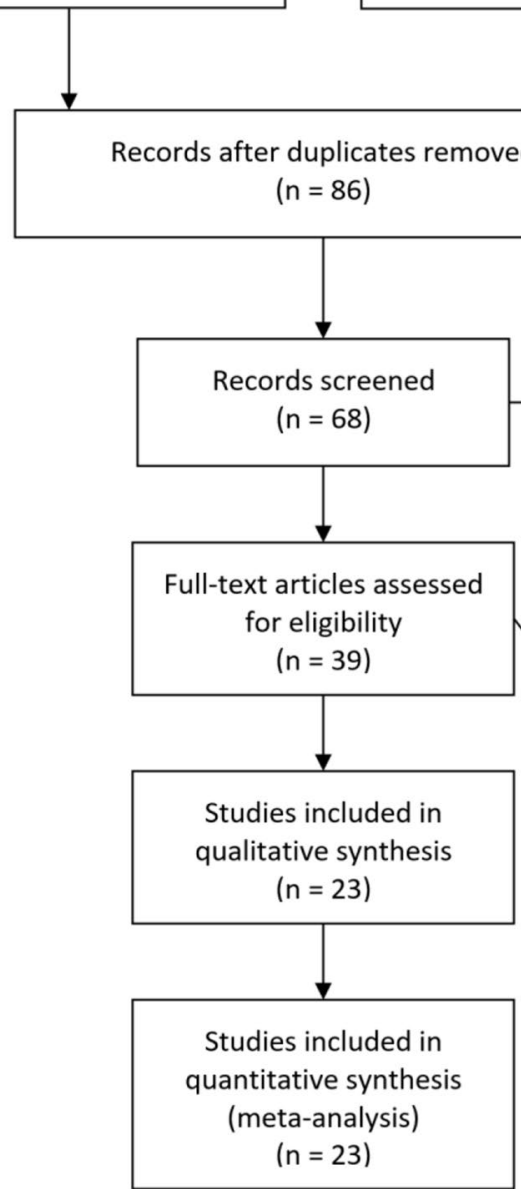

Records excluded $(n=18)$

Full-text articles excluded, with reasons $(n=16)$

Review articles: 5

Study with no relevant data: 3

PPI/H2RA use data not available: 1

Data presented as SBP episodes: 1

No control patients in the study: 1

Primary outcome is SBP recurrence: 1

Combined PPI/H2RA use data: 1

No extractable data: 3

Fig. 1 Flow diagram of studies included in the meta-analysis. SBP spontaneous bacterial peritonitis 
articles were excluded. As a result, we identified 23 studies that met our inclusion criteria [7-11, 21-38].

The detailed characteristics of the included studies are shown in Table 1. A total of 10,386 patients were included in the meta-analysis, $88.9 \%(9,236)$ of whom were part of cohort studies. There were 7 case-control studies and 16 cohort studies. These studies were conducted in North America, South America, Europe, and Asia. All studies adjusted the impact of confounders when assessing the association between PPIs use and SBP development except one study made by de Vos et al. [27]. The potential confounders most often adjusted for were age, ChildTurcotte-Pugh class, and Model for End-stage Liver Disease score. Only eight studies were performed with a multi-center design. The median NOS score for these studies was 7 (range, 5-8). Among the 23 included studies, 15 studies were moderate-quality studies (i.e., NOS scores were between 5 and 7) and 8 studies demonstrated a relatively high quality (i.e., NOS scores $>7$; Table 1).

\section{Meta-analysis}

The overall analysis of all 23 studies found that PPIs use was significantly associated with risk of SBP $(\mathrm{OR}=1.80$, 95\% CI 1.41-2.31, $p<0.00001)$, with significant heterogeneity across studies $\left(I^{2}=72 \%, p<0.00001\right)$. For the case-control studies, the pooled OR $(95 \% \mathrm{CI})$ was 2.62 $\left(1.94-3.54 ; p=0.36 ; I^{2}=10 \%\right)$. For the cohort studies, the pooled OR was 1.55 (95\% CI 1.16-2.06, $p<0.00001$; $I^{2}=74 \%$; Fig. 2).

Subgroup analysis was also carried out separately for high-quality and moderate-quality studies. The pooled OR for high-quality studies was 1.65 (95\% CI 1.19-2.29, $p=0.10 ; I^{2}=41 \%$ ), and the pooled OR for moderate quality studies was 1.87 (95\% CI 1.34-2.62, $p<0.00001$;

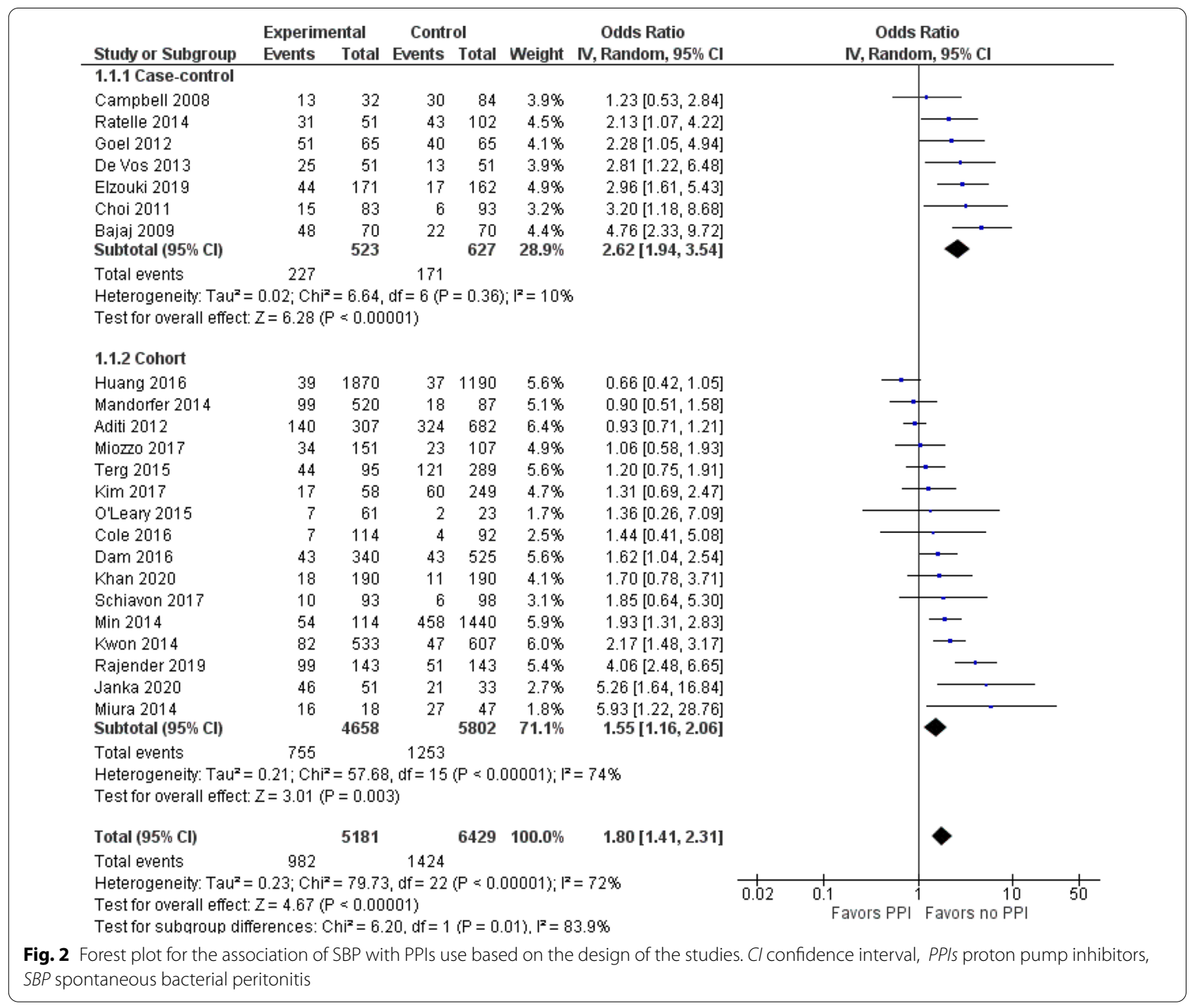


$I^{2}=79 \%$; Fig. 3). The funnel plot for possible publication bias appeared asymmetrical on visual inspection, and Egger's test confirmed asymmetry (intercept $=-0.05$, $\mathrm{SE}=0.27, p=0.850$ two-tailed); Fig. 4 .

\section{Discussion}

This is the largest meta-analysis on the association between PPI use and risk of developing SBP in cirrhotic patients with/without ascites. This study involving 10,386 patients from 23 observational studies found statistically significant but quantitatively small associations between the development of SBP and the use of PPIs. The pooled data showed that PPIs use was associated with a 1.8-fold increased risk of developing SBP for cirrhotic patients. However, this harmful association was limited to cohort studies. The data from case-control studies demonstrated no causal relationships between the use of PPIs and SBP. The association was not statistically significant in the high-quality studies subgroup.

PPIs are used widely in clinical practice for a broad range of indications in patients. Indications for PPIs include the treatment of peptic ulcer disease, gastroesophageal reflux disease, Zollinger-Ellison syndrome, NSAID-associated ulcers, and eradication of Helicobacter pylori $[39,40]$. They are also often used in patients with cirrhosis sometimes in the absence of a specific acid-related disease, with the aim of preventing peptic complications in patients with variceal or hypertensive gastropathic bleeding receiving multidrug treatment [41]. The use of this class of drugs seems more habitrelated than evidence-based eventually leading to compromise patient safety and increase health costs [41]. Healthcare providers managing patients with cirrhosis should be aware of the fact that the use of PPIs is not

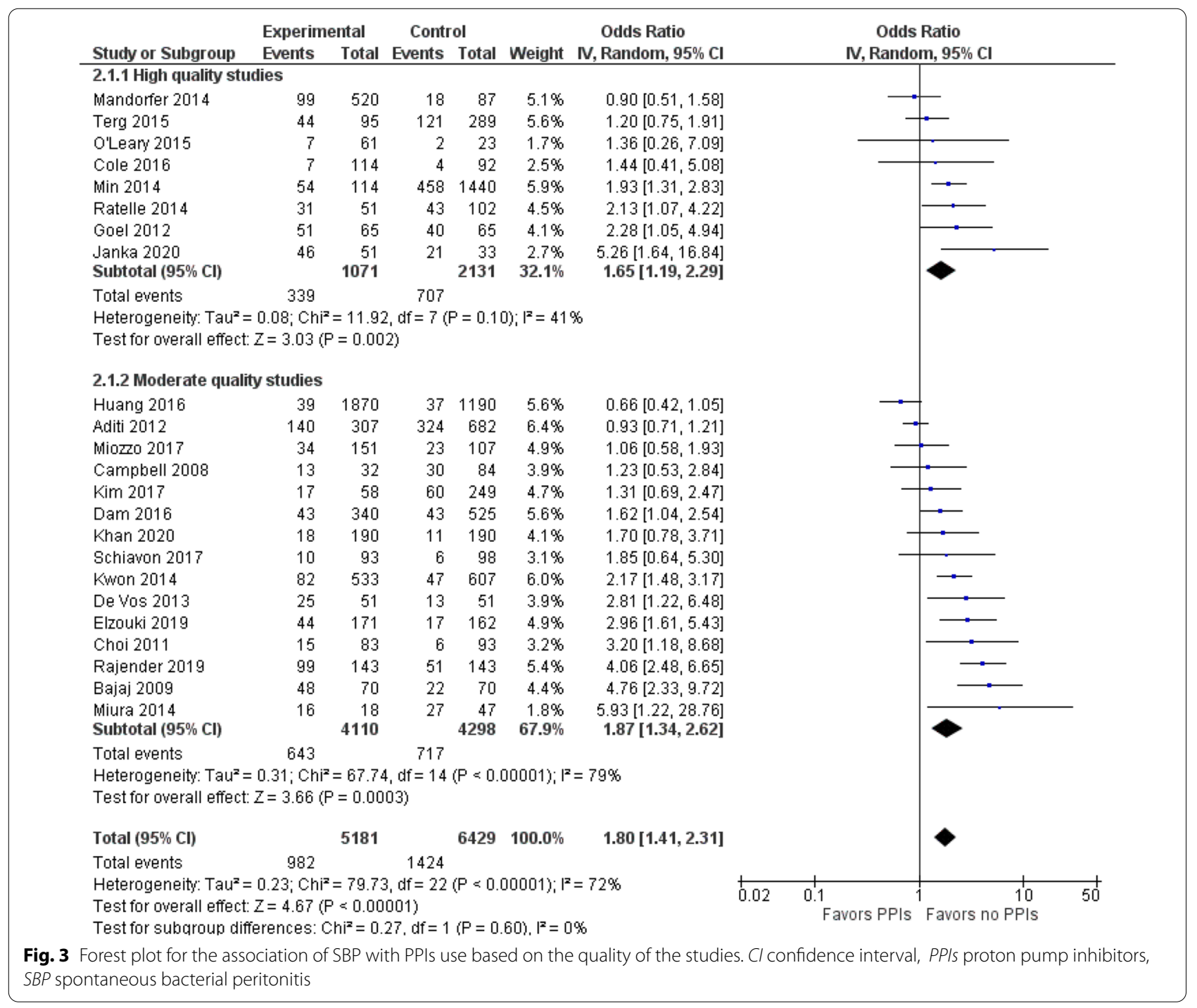




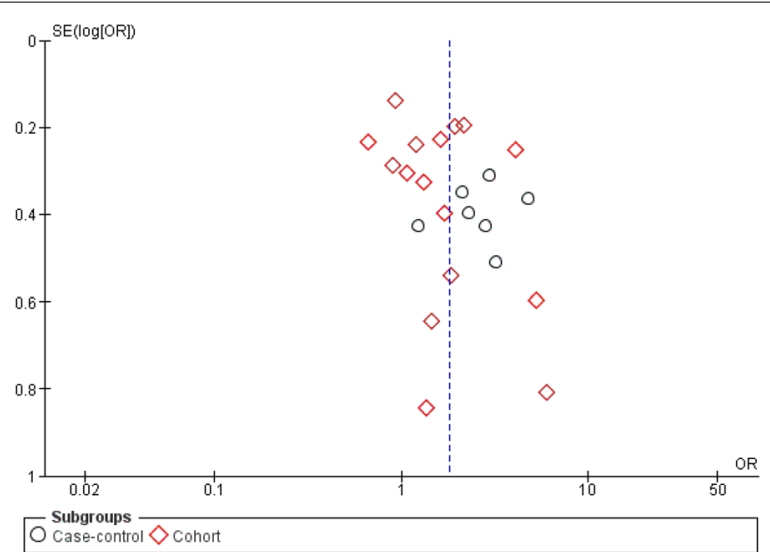

Fig. 4 Funnel plot to evaluate publication bias (PPIs use and development of SBP). OR odds ratio, PPI proton pump inhibitor, SBP spontaneous bacterial peritonitis

justified in a majority of these patients and should make every effort to evaluate and reassess actively the existing PPI therapy. The use of PPIs by prescribers should be judicious and restricted for indications of proven benefit only.

Most studies involved in our systematic review showed that there was a risk between the use of PPIs and the development of SBP [7, 9, 10, 22, 24-26, 28-31, 33, 34, $36,37]$, although few other included studies opposed this association [8, 21, 23, 27, 32, 35, 38]. The difference may be due to the patients with significant liver damage in the former fifteen studies. In addition, the mutant strains and its types, dosage of drugs may affect the results during treatment. The PPIs use and its association with the incidence of SBP in patients with cirrhosis is controversial, probably reflecting the heterogeneity of included patients across the studies and other methodological issues, such as retrospective design and insufficient follow-up. In addition, detrimental effects of PPIs may be restricted to specific subgroups, such as patients with decompensated cirrhosis, especially in the presence of ascites.

Although three latest previous systematic reviews have attempted to evaluate this association [12-14], our review is more current and more comprehensive. We included 21 published studies [7-11, 22-37] and 2 published abstracts [21,38], with a higher patient population $(n=10,386)$; and the number of published studies in our analysis exceeds that in previous reviews. The inclusion of four studies published recently [28, 30, 31, 37] to our meta-analysis made a more precise estimate of the pooled OR effect size to evaluate PPI use and its association with incidence of SBP in cirrhotic patients.

\section{Limitations}

There are several limitations to our findings. First, the included studies are observational in nature and, therefore, have intrinsic shortcomings, including differences in populations and possible unidentified confounders. Although some of these studies have suggested an association between PPIs therapy and SBP, they cannot establish causality with certainty. Well-designed, multi-center trials are needed for this purpose. To date, there are no prospective clinical trials, randomizing cirrhotic patients with/without ascites to PPIs use or non-use, which could be difficult to justify on clinical, ethical, or economic bases. Second, adjustment for the duration of PPIs was not possible therapy because many of the included studies did not report on the relevant data. Both duration and dose of PPI treatment should be related to the risk for the outcome of interest to support a causal association. Last, the exclusion of studies published in languages other than English may have impacted the richness of the data included in this review.

\section{Conclusion}

Our meta-analysis of observational studies found that PPI use was associated with an increased risk of SBP in patients with cirrhosis with/without ascites. However, the magnitude of the possible association diminished when analysis focused on higher quality data that were more robust. PPIs can be used in the treatment of various therapeutic indications; nevertheless, PPIs therapy should be administered with caution in cirrhotic patients. Future studies maybe need to clarify the relationship between the occurrence of SBP and the type and dose of PPI in cirrhotic patients.

\section{Abbreviations}

SBP: Spontaneous bacterial peritonitis; PPIs: Proton pump inhibitors; PRISMA Preferred Reporting Items for systematic reviews and meta-Analyses; NOS: Newcastle-Ottawa scale; PMN: Polymorphonuclear leukocyte.

\section{Acknowledgement}

We would like to thank authors and their colleagues who contributed to the availability of evidence needed to compile this article.

\section{Authors' contributions}

SA, AA, ZA, AAR and AAO contributed equally to this article. SA, AA and ZA.Conception, proposal, data collection, data analysis, and manuscript preparation. All authors read and approved the final manuscript.

Funding

This research received no external funding.

Availability of data and materials

Data are available upon request, please contact author for data requests.

\section{Declarations}

Ethics approval and consent to participate

Not applicable. 


\section{Consent for publication}

All authors agreed to this publication.

\section{Competing interest}

The authors have no conflicts of interest to declare.

\section{Author details}

${ }^{1}$ Administration of Pharmaceutical Care, Al-Ahsa Health Cluster, Ministry of Health, Al-Ahsa, Saudi Arabia. ${ }^{2}$ Research Center, Almoosa Specialist Hospital, Al-Ahsa, Saudi Arabia. ${ }^{3}$ College of Nursing, Princess Nourah Bint Abdul Rahman University, Riyadh, Saudi Arabia. ${ }^{4}$ School of Nursing, University of Wollongong, Wollongong, Australia. ${ }^{5}$ Department of Paediatrics, College of Medicine, King Faisal University, Al-Ahsa, Saudi Arabia. ${ }^{6}$ Research Center, Dr. Sulaiman Al Habib Medical Group, Riyadh, Saudi Arabia. ${ }^{7}$ College of Medicine, Alfaisal University, Riyadh, Saudi Arabia. ${ }^{8}$ Molecular Diagnostic Laboratory, Johns Hopkins Aramco Healthcare, Dhahran, Saudi Arabia.

Received: 7 December 2020 Accepted: 11 March 2021 Published online: 19 March 2021

\section{References}

1. Koulaouzidis A, Bhat S, Karagiannidis A, Tan W, Linaker B. Spontaneous bacterial peritonitis. Postgrad Med J. 2007;83(980):379-83.

2. Runyon BA. The evolution of ascitic fluid analysis in the diagnosis of spontaneous bacterial peritonitis. Am J Gastroenterol. 2003;98(8):1675.

3. Fernández J, Navasa M, Gómez J, Colmenero J, Vila J, Arroyo V, Rodés J. Bacterial infections in cirrhosis: epidemiological changes with invasive procedures and norfloxacin prophylaxis. Hepatology. 2002;35(1):140-8.

4. Tandon P, Garcia-Tsao G. Renal dysfunction is the most important independent predictor of mortality in cirrhotic patients with spontaneous bacterial peritonitis. Clin Gastroenterol Hepatol. 2011;9(3):260-5.

5. Guarner C, Runyon BA, Young S, Heck M, Sheikh MY. Intestinal bacterial overgrowth and bacterial translocation in cirrhotic rats with ascites. J Hepatol. 1997;26(6):1372-8.

6. Pardo A, Bartolí R, Lorenzo-Zúñiga V, Planas R, Viñado B, Riba J, Cabré E, Santos J, Luque T, Ausina V. Effect of cisapride on intestinal bacterial overgrowth and bacterial translocation in cirrhosis. Hepatology. 2000;31(4):858-63.

7. Goel GA, Deshpande A, Lopez R, Hall GS, van Duin D, Carey WD. Increased rate of spontaneous bacterial peritonitis among cirrhotic patients receiving pharmacologic acid suppression. Clin Gastroenterol Hepatol. 2012;10(4):422-7.

8. Mandorfer M, Bota S, Schwabl P, Bucsics T, Pfisterer N, Summereder C, Hagmann M, Blacky A, Ferlitsch A, Sieghart W. Proton pump inhibitor intake neither predisposes to spontaneous bacterial peritonitis or other infections nor increases mortality in patients with cirrhosis and ascites. PLOS ONE. 2014;9(11).

9. O'Leary JG, Reddy KR, Wong F, Kamath PS, Patton HM, Biggins SW, Fallon MB, Garcia-Tsao G, Subramanian RM, Malik R. Long-term use of antibiotics and proton pump inhibitors predict development of infections in patients with cirrhosis. Clinical Gastroenterol Hepatol. 2015;13(4):753-9. e2.

10. Ratelle M, Perreault S, Villeneuve J-P, Tremblay L. Association between proton pump inhibitor use and spontaneous bacterial peritonitis in cirrhotic patients with ascites. Canadian J Gastroenterol Hepatol. 2014;28(6):330-4.

11. Terg R, Casciato P, Garbe C, Cartier M, Stieben T, Mendizabal M, Niveyro C, Benavides J, Marino M, Colombato L. Proton pump inhibitor therapy does not increase the incidence of spontaneous bacterial peritonitis in cirrhosis: a multicenter prospective study. J Hepatol. 2015;62(5):1056-60.

12. Khan MA, Kamal S, Khan S, Lee WM, Howden CW. Systematic review and meta-analysis of the possible association between pharmacological gastric acid suppression and spontaneous bacterial peritonitis. Eur J Gastroenterol Hepatol. 2015;27(11):1327-36.

13. $Y u T$, Tang $Y$, Jiang $L$, Zheng $Y$, Xiong $W$, Lin L. Proton pump inhibitor therapy and its association with spontaneous bacterial peritonitis incidence and mortality: a meta-analysis. Dig Liver Dis. 2016;48(4):353-9.
14. Dong H, Luo S, Dong Y, Feng W, Wei Y. The use of PPI is associated with spontaneous bacterial peritonitis in cirrhotic patients of different ethnic groups: a meta-analysis. Int J Clin Exp Med. 2016;9(2):1227-35.

15. Wells GA, Tugwell P, O'Connell D, Welch V, Peterson J, Shea B, Losos M. The Newcastle-Ottawa Scale (NOS) for assessing the quality of nonrandomized studies in meta-analyses. 2015.

16. Moher D, Liberati A, Tetzlaff J, Altman DG, Group P. Preferred reporting items for systematic reviews and meta-analyses: the PRISMA statement. PLoS Med. 2009;6(7):e1000097.

17. Davies HTO, Crombie IK, Tavakoli M. When can odds ratios mislead? BMJ. 1998:316(7136):989-91.

18. Higgins JP, Thompson SG. Quantifying heterogeneity in a meta-analysis. Stat Med. 2002;21(11):1539-58.

19. Higgins JP, Thompson SG, Deeks JJ, Altman DG. Measuring inconsistency in meta-analyses. BMJ. 2003;327(7414):557-60.

20. Egger M, Smith GD, Schneider M, Minder C. Bias in meta-analysis detected by a simple, graphical test. BMJ. 1997;315(7109):629-34.

21. Aditi A, Crippin JS, Abhishek A. Sa1014 Role of proton pump inhibitors in the development of spontaneous bacterial peritonitis amongst cirrhotics; a retrospective cohort study. Gastroenterol. 2012;142(5):S-946.

22. Bajaj JS, Zadvornova Y, Heuman DM, Hafeezullah M, Hoffmann RG, Sanyal AJ, Saeian K. Association of proton pump inhibitor therapy with spontaneous bacterial peritonitis in cirrhotic patients with ascites. Am J Gastroenterol. 2009;104(5):1130-4.

23. Campbell MS, Obstein K, Reddy KR, Yang Y-X. Association between proton pump inhibitor use and spontaneous bacterial peritonitis. Dig Dis Sci. 2008;53(2):394-8.

24. Choi EJ, Lee HJ, Kim KO, Lee SH, Eun JR, Jang BI, Kim TN. Association between acid suppressive therapy and spontaneous bacterial peritonitis in cirrhotic patients with ascites. Scand J Gastroenterol. 2011;46(5):616-20.

25. Cole H, Pennycook S, Hayes P. The impact of proton pump inhibitor therapy on patients with liver disease. Aliment Pharmacol Ther. 2016;44(11-12):1213-23.

26. Dam G, Vilstrup H, Watson $H$, Jepsen P. Proton pump inhibitors as a risk factor for hepatic encephalopathy and spontaneous bacterial peritonitis in patients with cirrhosis with ascites. Hepatology. 2016;64(4):1265-72.

27. de Vos M, De Vroey B, Garcia BG, Roy C, Kidd F, Henrion J, Deltenre P. Role of proton pump inhibitors in the occurrence and the prognosis of spontaneous bacterial peritonitis in cirrhotic patients with ascites. Liver Int. 2013;33(9):1316-23.

28. Elzouki A-N, Neffati N, Rasoul FA, Abdallah A, Othman M, Waness A. Increased risk of Spontaneous bacterial peritonitis in cirrhotic patients using proton pump inhibitors GE-Portuguese. J Gastroenterol. 2019;26(2):83-9.

29. Huang K-W, Kuan Y-C, Luo J-C, Lin C-L, Liang J-A, Kao C-H. Impact of longterm gastric acid suppression on spontaneous bacterial peritonitis in patients with advanced decompensated liver cirrhosis. Eur J Intern Med. 2016;32:91-5

30. Janka T, Tornai T, Borbély B, Tornai D, Altorjay I, Papp M, Vitális Z. Deleterious effect of proton pump inhibitors on the disease course of cirrhosis. Eur J Gastroenterol Hepatol. 2020;32(2):257-64.

31. Khan TU, Khan W, Iqbal S. Frequency of spontaneous bacterial peritonintis in chronic liver disease patients using proton pump inhibitors. Professional Medical Journal. 2020;27(3).

32. Kim JH, Lim KS, Min YW, Lee H, Min BH, Rhee PL, Kim JJ, Koh KC, Paik SW. Proton pump inhibitors do not increase the risk for recurrent spontaneous bacterial peritonitis in patients with cirrhosis. J Gastroenterol Hepatol. 2017:32(5):1064-70.

33. Kwon JH, Koh SJ, Kim W, Jung YJ, Kim JW, Kim BG, Lee KL, Im JP, Kim YJ, Kim JS. Mortality associated with proton pump inhibitors in cirrhotic patients with spontaneous bacterial peritonitis. J Gastroenterol Hepatol. 2014;29(4):775-81.

34. Min Y, Lim K, Min BH, Gwak GY, Paik Y, Choi M, Lee J, Kim J, Koh K, Paik S. Proton pump inhibitor use significantly increases the risk of spontaneous bacterial peritonitis in 1965 patients with cirrhosis and ascites: a propensity score matched cohort study. Aliment Pharmacol Ther. 2014;40(6):695-704. 
35. Miozzo SA, John JA, Appel-da-Silva MC, Dossin IA, Tovo CV, Mattos AA. Influence of proton pump inhibitors in the development of spontaneous bacterial peritonitis. World J Hepatol. 2017;9(35):1278.

36. Miura K, Tanaka A, Yamamoto T, Adachi M, Takikawa H. Proton pump inhibitor use is associated with spontaneous bacterial peritonitis in patients with liver cirrhosis. Intern Med. 2014;53(10):1037-42.

37. Rajender A, Choudhary P, Mathur S, Bhargava R, Upadhyay S, Nepalia S. Proton pump inhibitor: a risk factor for spontaneous bacterial peritonitis in Indian cirrhotics decompensated with ascites. Int J Res Med Sci. 2019;7(2):378

38. Schiavon L, Silva T, Fischer J, Narciso-Schiavon J. proton pump inhibitors and prognosis of cirrhosis-searching for the balance point. Aliment Pharmacol Ther. 2017;45(2):378-9.

39. Welage LS, Berardi RR. Evaluation of omeprazole, lansoprazole, pantoprazole, and rabeprazole in the treatment of acid-related diseases. Journal of the American Pharmaceutical Association (1996). 2000;40(1):52-62.
40. Savarino V, Dulbecco P, de Bortoli N, Ottonello A, Savarino E. The appropriate use of proton pump inhibitors (PPIs): need for a reappraisal. Eur Intern Med. 2017:37:19-24.

41. Lodato F, Azzaroli F, Di Girolamo M, Feletti V, Cecinato P, Lisotti A, Fest D, Roda E, Mazzella G. Proton pump inhibitors in cirrhosis: tradition or evidence based practice? World J Gastroenterol. 2008;14(19):2980.

\section{Publisher's Note}

Springer Nature remains neutral with regard to jurisdictional claims in published maps and institutional affiliations.
Ready to submit your research? Choose BMC and benefit from:

- fast, convenient online submission

- thorough peer review by experienced researchers in your field

- rapid publication on acceptance

- support for research data, including large and complex data types

- gold Open Access which fosters wider collaboration and increased citations

- maximum visibility for your research: over 100M website views per year

At BMC, research is always in progress.

Learn more biomedcentral.com/submissions 